\title{
Introducing the Canadian Thoracic Society Framework for Guideline Dissemination and Implementation, with Concurrent Evaluation
}

\author{
Samir Gupta MSc MD FRCPC1 ${ }^{1}$ Christopher Licskai BSc MD FRCPC ${ }^{2}$, \\ Anne Van Dam ${ }^{3}$, Louis-Philippe Boulet MD FRCPC FCCP 4
}

\begin{abstract}
S Gupta, C Licskai, A Van Dam, L-P Boulet. Introducing the Canadian Thoracic Society Framework for Guideline Dissemination and Implementation, with Concurrent Evaluation. Can Respir J 2013;20(4):263-264.

The Canadian Thoracic Society (CTS) is leveraging its strengths in guideline production to enable respiratory guideline implementation in Canada. The authors describe the new CTS Framework for Guideline Dissemination and Implementation, with Concurrent Evaluation, which has three spheres of action: guideline production, implementation infrastructure and knowledge translation (KT) methodological support. The Canadian Institutes of Health Research 'Knowledge-to-Action' process was adopted as the model of choice for conceptualizing KT interventions. Within the framework, new evidence for formatting guideline recommendations to enhance the intrinsic implementability of future guidelines were applied. Clinical assemblies will consider implementability early in the guideline production cycle when selecting clinical questions, and new practice guidelines will include a section dedicated to KT. The framework describes the development of a web-based repository and communication forum to inventory existing KT resources and to facilitate collaboration and communication among implementation stakeholders through an online discussion board. A national forum for presentation and peer-review of proposed $\mathrm{KT}$ projects is described. The framework outlines expert methodological support for KT planning, development and evaluation including a practical guide for implementers and a novel 'Clinical Assembly - KT Action Team', and inkind logistical support and assistance in securing peer-reviewed funding.
\end{abstract}

Key Words: Implementation; Guidelines; Knowledge translation
Présentation du cadre de diffusion et de mise en ouvre des lignes directrices de la Société canadienne de thoracologie, accompagné d'une évaluation concomitante

La Société canadienne de thoracologie (SCT) tire profit de ses points forts en production de lignes directrices pour catalyser la mise en œuvre des lignes directrices en pneumologie au Canada. Les auteurs décrivent le nouveau cadre de la SCT pour diffuser et mettre en œuvre les lignes directrices, accompagné d'une évaluation concomitante, et qui s'associe à trois champs d'action : la production de lignes directrices, l'infrastructure de mise en œuvre et le soutien méthodologique du transfert du savoir (TS). La SCT a adopté le processus des « connaissances à la pratique » des Instituts de recherche en santé du Canada comme modèle pour conceptualiser les interventions de TS. Dans ce cadre, elle a mis en pratique les nouvelles données probantes sur la présentation des recommandations des lignes directrices, de manière à favoriser la mise en œuvre intrinsèque des futures lignes directrices. Des assemblées cliniques évalueront la possibilité de leur mise en œuvre dès le début du cycle de production, au moment de sélectionner les questions cliniques, et les prochaines lignes directrices de pratique incluront une rubrique consacrée au TS. Le cadre présente le mode d'élaboration d'un référentiel virtuel et d'un forum de communication pour répertorier les ressources de TS en place et pour favoriser la collaboration et la communication entre les intervenants responsables de la mise en œuvre, par l'entremise d'un forum de discussion virtuel. Un forum national de présentation et de révision par les pairs des projets de TS est exposé. Le cadre fait ressortir le soutien méthodologique d'experts pour la planification, l'élaboration et l'évaluation du TS, y compris un guide de pratique pour les responsables de la mise en œuvre, une " Assemblée clinique - équipe d'action de TS » novatrice, ainsi qu'un soutien logistique et de l'aide d'ordre non financier pour obtenir un financement révisé par les pairs.
$\mathrm{T}$ he Canadian Thoracic Society (CTS) represents more than 680 respirologists, researchers and physicians involved in respiratory health, with a key mandate to improve the health of Canadians with respiratory diseases through promotion of evidence-based respiratory care. For four decades, the CTS has been a world-leader in producing and disseminating high-quality clinical practice guidelines across a spectrum of respiratory conditions. In 2007, the CTS created the Canadian Respiratory Guidelines Committee (CRGC) to establish a new, uniform and best evidence-based standard for CTS guideline production methodology (1) and enable a new organizational focus on guideline implementation with concurrent evaluation.

Since that time, guideline writers in individual clinical assemblies (specific disease/topic guideline committees) have successfully learned and adopted these methods, and have applied them to produce new guidelines and standards in the following areas: pulmonary vascular disease; home mechanical ventilation; asthma; chronic obstructive pulmonary disease; sleep disordered breathing; spirometry; and tuberculosis (2). We have also created the Canadian Respiratory Guidelines website, which has been a rapidly growing vehicle for passive guideline dissemination, with more than 75,000 annual visits from users in 16 countries this past year. We now present a detailed organizational approach to guideline implementation: the CTS Framework for Guideline Dissemination and Implementation, with Concurrent Evaluation.

\section{FRAMEWORK}

The elements of this framework are intended to support clinical assembly members and other interested parties in planning, designing and leading knowledge translation (KT) activities beginning with guideline production, continuing throughout implementation and ending with objective evaluation. It consists of three areas: KT methodology; communication, collaboration and KT resource sharing; and direct support for KT planning, development and evaluation.

\section{KT methodology}

Adoption of an overarching theoretical model to guide KT activities: Several theories, models and frameworks have sought to explain and/ or predict behaviour change and an overall approach is required to enable implementers to use these behaviour change theories to plan successful KT interventions. In 2006, Graham et al (6) studied more than 60 planned action models, characterizing common elements in an effort to devise a comprehensive but practical framework for KT activities. This approach, termed the 'Knowledge-to-Action' process, has since been broadly espoused by implementation researchers, recommended by the Canadian Institutes of Health Research (CIHR) (4) and herein designated as the CTS model for conceptualizing and developing KT interventions (5).

Adoption of intrinsic KT strategies at the guideline production stage: Conventional implementation efforts begin after guideline

${ }^{1}$ The Keenan Research Centre in the Li Ka Shing Knowledge Institute of St Michael's Hospital, Department of Medicine, University of Toronto

Toronto; ${ }^{2}$ Western University, London; ${ }^{3}$ Canadian Lung Association, Ottawa, Ontario; ${ }^{4}$ Institut universitaire de cardiologie et de pneumologie

de Québec, Université Laval, Québec

Correspondence and reprints: Canadian Thoracic Society, 300-1750 Courtwood Crescent, Ottawa, Ontario K2C 2B5. Telephone 613-569-6411,

fax613-569-8860,e-mail info@lung.ca 
production. The CTS strategic plan seeks to promote a more 'upstream' approach. Clinical assemblies are encouraged to consider implementability and seek input from knowledge users at the beginning of the guideline production process. When selecting clinical questions to address within guidelines, clinical assemblies will be asked to consult with end users about which questions are most relevant and to consider the following factors influencing implementability: the magnitude of the knowledge-to-care gap; target audience(s); known barriers and supports to implementation; possible implementation strategies; societal impact; and relevant metrics to be used in evaluating the success of the implementation program. Future guidelines will also include a dedicated KT section that will describe each of these factors in relation to each of the recommendations considered by guideline producers to be top priorities for KT activities. Research has also shown that features that are 'intrinsic' to guidelines, including the format and content of the recommendations, influence user perceptions and guideline uptake (6). The CTS intends to use this body of research to improve the intrinsic implementability of its guidelines by formatting recommendations in accordance with this evidence.

\section{Communication, collaboration and $\mathrm{KT}$ resource sharing}

Creation of a repository of existing $\mathrm{KT}$ resources, programs and projects: Although KT is a relatively new field, and the need for KT in respiratory diseases in particular has only recently gained wide recognition, experience and resources are beginning to grow both in Canada and around the world. Accordingly, to both minimize duplication and to benefit from previous experience, common interests and skills, the CRGC plans to develop a repository of respiratory-specific KT material for would-be implementers. This implementation 'toolbox' would include information about existing knowledge tools, such as continuing professional development resources and other such tools, many of which are available online; planned, ongoing and previous local, provincial and national implementation programs and projects; and ongoing KT studies in the respiratory field (as documented by granting agencies and on trial registers). The CTS will approach its members, guideline authors (experts), respiratory organizations, provincial lung associations and health ministries to contribute to this repository, which will be linked to the CTS website (www.respiratoryguidelines.ca/).

Facilitation of communication among key stakeholders: The CTS will establish mechanisms for identification and communication among respiratory knowledge implementers in Canada and internationally, including practitioners, researchers, funders, health advocacy organizations (ie, provincial lung associations) and decision makers (ie, health ministry representatives). Examples include a KT discussion board hosted on the CRGC website, and a forum for presentation and peer-review of proposed KT projects at the annual Canadian Respiratory Conference.

\section{Direct support for KT planning, development and evaluation}

Development of a practical guide to support implementers: The KTA process provides excellent theoretical underpinnings by which to both identify relevant gaps requiring KT initiatives and guide principles of intervention design and effect measurement. However, guideline committees have requested a systematic guide with practical instructions for each distinct stage in the KTA cycle. Several organizations have developed KT guides for specific types of implementers and content areas. Informed by these existing resources, the CRGC will complete a detailed practical guide and corresponding training program for its clinical assemblies.

Methodological support: The CTS will support implementation projects through a 'Clinical Assembly - KT Action Team' consisting of members of the relevant clinical assembly (content experts) and KT experts from the CRGC. KT experts will help to maintain project alignment with the CIHR KT Framework and offer methodological and evaluation support. The CTS will offer logistical support for these implementation projects. Only projects with formal evaluative components will be supported through this mechanism.
Initially, implementation projects will originate from within clinical assemblies; however, we anticipate that the KT repository will create opportunities for CTS assemblies to align with current and future projects to maximize efficiency. Trainees and junior investigators interested in KT will be encouraged to join the clinical assembly as ad hoc members for specific KT projects to build on current and future KT capacity.

Funding support: The CTS will create a web-based inventory of existing KT program and research funding sources to help interested parties identify opportunities for KT project funding. The Clinical Assembly - KT Action Team will also play an active role in grant and proposal development. The CTS will provide a letter of support for relevant funding applications.

\section{CONCLUSIONS}

The CTS is excited to leverage its existing strengths in guideline production to transition to a new focus on active guideline implementation. Although other respiratory organizations have emphasized the importance of implementation activities and have proposed corresponding strategies $(7,8)$, none have presented a dedicated and multifaceted framework approach. Over the next five years, the success of this approach will be determined by the number of new implementation projects that arise from the framework, and their measured impact on health care processes and patient outcomes. We hope to enable the use of high-quality Canadian guidelines as a springboard for active KT and, in doing so, usher in a new era of respiratory guideline implementation and improved respiratory health for all Canadians.

ACKNOWLEDGEMENTS: The authors thank members of the CTS Asthma Clinical Assembly for their feedback and suggestions on the CTS/ CRGC KT Strategy.

AUTHOR CONTRIBUTIONS: SG, LPB, CL and AVD contributed to content and revisions, and SG drafted the manuscript.

DISCLOSURES: SG, CL, AVD and LPB have no financial disclosures or conflics of interest to declare.

DISCLAIMER: This work originated from The Keenan Research Centre in the Li Ka Shing Knowledge Institute of St Michael's Hospital, Department of Medicine, University of Toronto, Toronto, Ontario.

\section{REFERENCES}

1. Gupta S, Bhattacharyya OK, Brouwers MC, et al. Canadian Thoracic Society: Presenting a new process for clinical practice guideline production. Can Respir J 2009;16:e62-e68.

2. Canadian Thoracic Society. The Canadian Respiratory Guidelines (CRGC) Site. 2013. < respiratoryguidelines.ca> (Accessed March 10, 2013).

3. Graham ID, Logan J, Harrison MB, et al. Lost in knowledge translation: Time for a map? J Contin Educ Health Profess 2006;26:13-24.

4. Canadian Institutes of Health Research. About Knowledge Translation at CIHR. 2009. <www.cihr-irsc.gc.ca/e/39158.html> (Accessed March 1, 2013).

5. KT Clearinghouse. The Knowledge-To-Action Cycle. 2011. $<$ http://ktclearinghouse.ca/knowledgebase/knowledgetoaction> (Accessed March 10, 2013).

6. Gagliardi AR, Brouwers MC, Bhattacharyya OK. The guideline implementability research and application network (GIRAnet): An international collaborative to support knowledge exchange: Study protocol. Implement Sci 2012;7:26.

7. Boulet L-P, FitzGerald JM, Levy ML, et al. A guide to the translation of the Global Initiative for Asthma (GINA) strategy into improved care. Eur Respir J 2012;39:1220-9.

8. Grimshaw JM, Schunemann HJ, Burgers J, et al. Disseminating and implementing guidelines: Article 13 in integrating and coordinating efforts in COPD guideline development. An official ATS/ERS workshop report. Proc Am Thorac Soc 2012;9:298-303. 


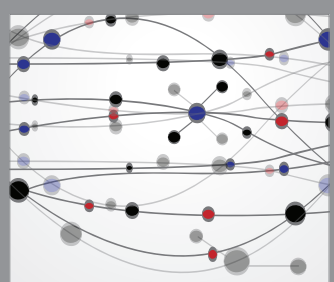

The Scientific World Journal
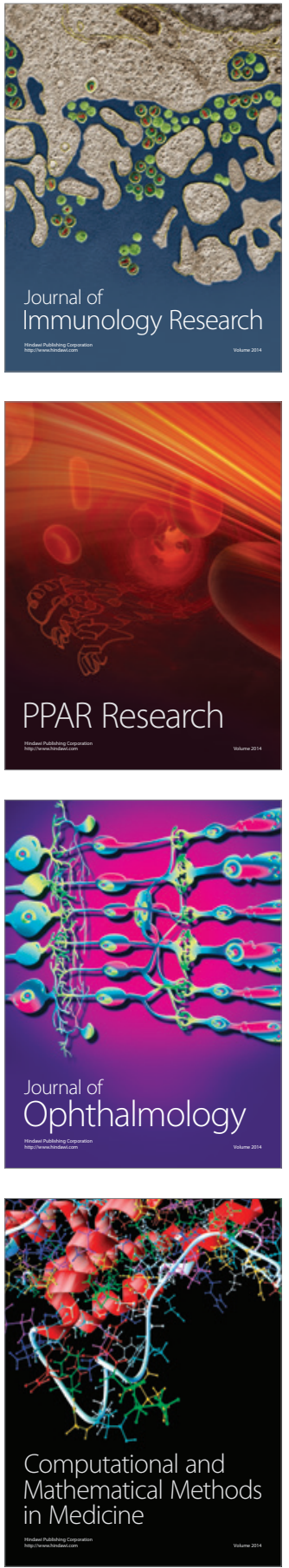

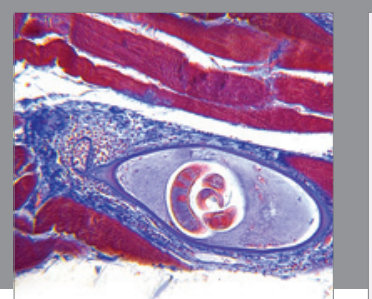

Gastroenterology Research and Practice

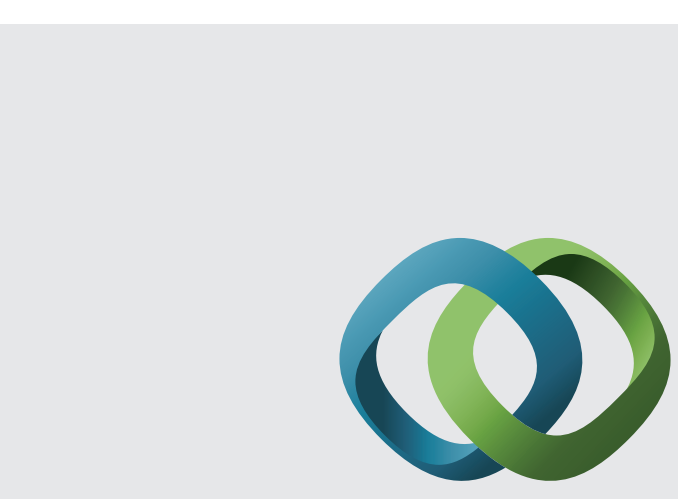

\section{Hindawi}

Submit your manuscripts at

http://www.hindawi.com
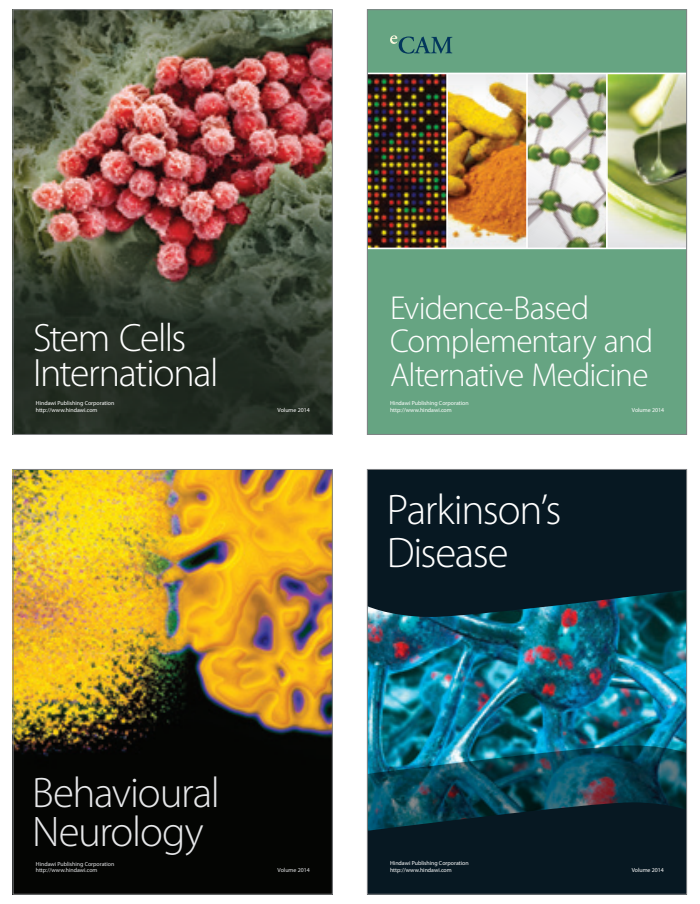
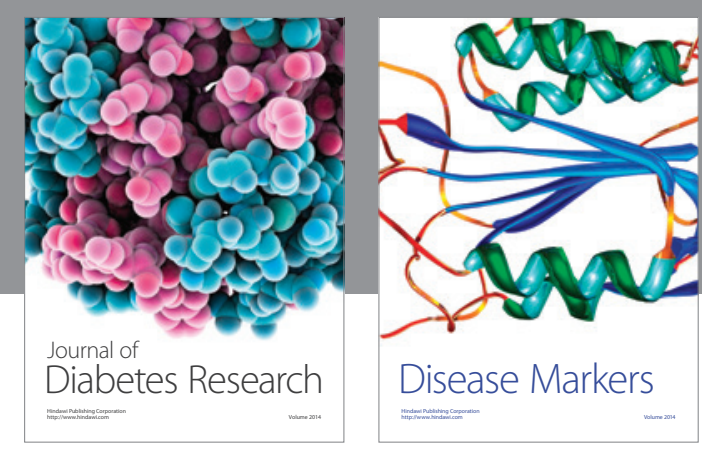

Disease Markers
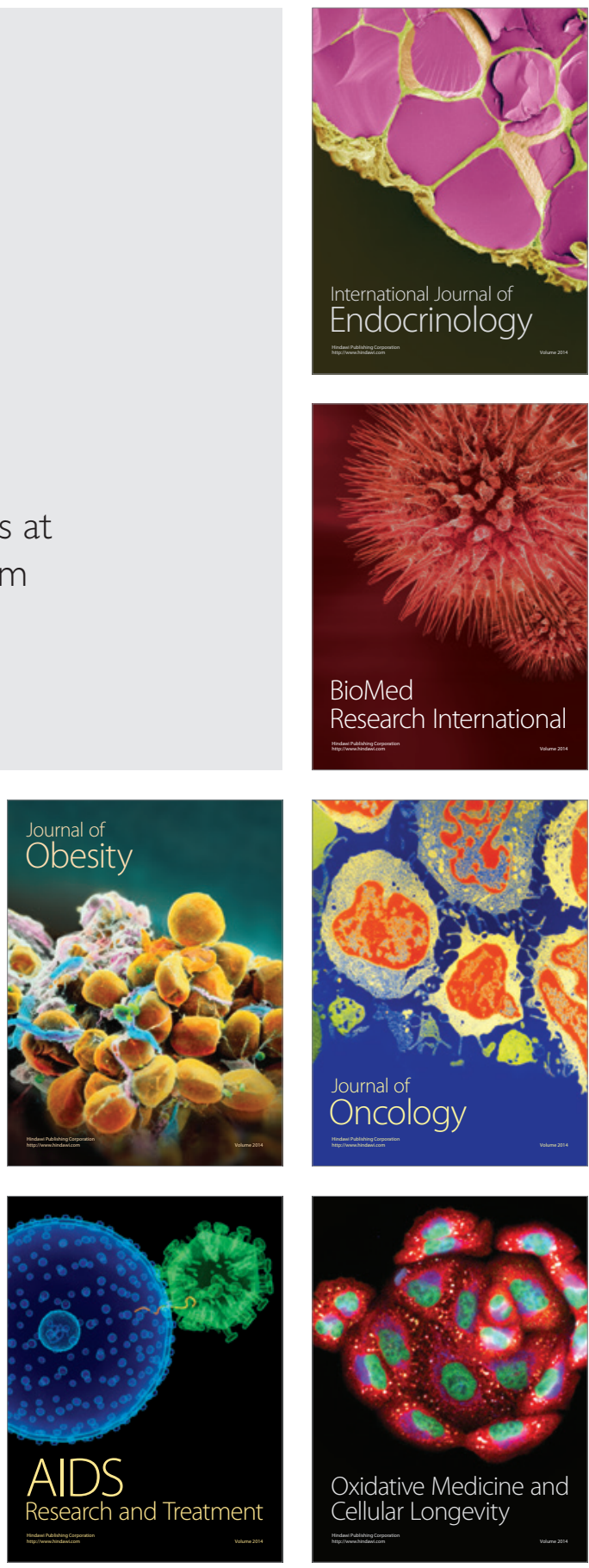